\title{
Design procedure for steel column bases with stiffeners
}

\author{
Marcin Górski ${ }^{1, *}$ \\ ${ }^{1}$ Rzeszów University of Technology, Department of Building Structures, ul. Poznańska 2, \\ 35-959 Rzeszów, Poland
}

\begin{abstract}
The procedure of calculation of steel column bases with stiffeners including plastic distribution of stresses in concrete has been shown. The strain model from section analysis, similar to model used in calculations of reinforced concrete columns has been used in this purpose. The assumption of linear strain of base plate under stiffeners and column has been made, according to Bernoulli-Euler Theory. The displacements of compressed part of columns bases have been associated with deformations of concrete foundation. Limitations of dimensions of compression zone have been defined based on results of FEM analysis. Ultimate compressive strain in the concrete under compression and bending, according to Eurocode 2 has been taken into consideration in the procedure. Deformation of base plate based on stiffness coefficients used in determining of rotational stiffness of steel joints has been assumed in the tensioned part. Incomplete utilisation of bolts resistance due to insufficient deformation has been also included. All the mentioned assumptions results in universal procedure that allows calculation of resistance of column bases under any combination of axial force and bending moment. Finally design example with an entire proceeding has been presented.
\end{abstract}

\section{Introduction}

Columns are elements of steel structures often subjected not only to axial force, but also to bending moment, which are transferred into foundations. It requires proper design of a column base. In the case of small values of bending moments, usually a simple base plate with suitable thickness is sufficient. Calculation of column bases with such geometry is shown in Eurocode 3 [1]. When the force transferred into foundation grows significantly, the single base plate becomes insufficient, so vertical stiffeners of base plate are required. The actual code [1] does not provide guidelines for calculations of column bases with such complex geometry. There are only procedures (e.g. Fisher's formula [2]) to analyse rigid column bases, based on assumption of elastic analysis and linear distribution of stress in concrete under column base, while Eurocode allows plastic analysis. The paper proposes a universal calculation procedure of steel column bases with stiffeners considering plastic stress distribution.

\footnotetext{
*Corresponding author: mgorski@prz.edu.pl
} 


\section{Assumptions of procedure}

\subsection{General}

The assumption of rigid column core and stiffeners has been made. It results in linear deformation of part of base plate under these elements. Therefore the model according to Bernoulli-Euler Theory can be used in the procedure. However, nonlinear behavior of concrete results in different centroid of foundation compared to steel column [3]. As a result the base plate is situated in discontinuity point of a structure, so the strain equation cannot be used directly. Instead of strain, total vertical displacements of distinctive points of base plate in compression and tension zone have been determined.

\subsection{Compression zone}

The column cross-section together with vertical stiffeners, enlarged on both sides by additional bearing width $c$ determines the available effective area of concrete (Fig. 1).

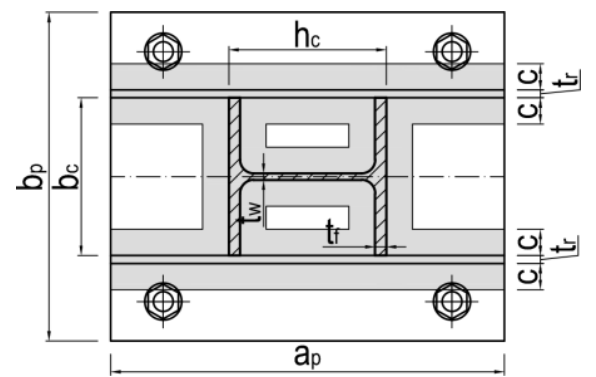

Fig. 1. Available effective part of concrete taken into account in calculations.

A simplified, rectangular distribution of stresses in compression zone of concrete has been assumed, which results in Eq. (1).

$$
x_{e f f}=\lambda \cdot x
$$

where:

$\lambda=0,8$ for concrete up to strength class C50/60 according to [4].

$x$ the distance from the ends of stiffeners, where the compressive strain is maximum, to the neutral axis.

The value of $x_{\text {eff }}$ should be set to achieve the equilibrium of vertical forces (resultant force in concrete should counterbalance the resistance of tension zone increased by the acting axial force).

The range of compression zone depends on the eccentricity of the compressive force (bending moment to axial force ratio). In the case of pure bending compressive stress in concrete occurs only in the zone located at the ends of stiffeners. Along with the increase of the axial force, the position of neutral axis moves towards the plate end in tension [5]. The FEM analysis by means of Autodesk Simulation Mechanical software has been conducted to verify these assumptions. The model of exemplary steel column base made of 8 -nodes brick and 4-nodes tetrahedral elements has been analyzed under various loads. The computations consider surface-to-surface contact, as well as nonlinear material models. Selected results of analysis are shown in Fig. 2 - 3. 


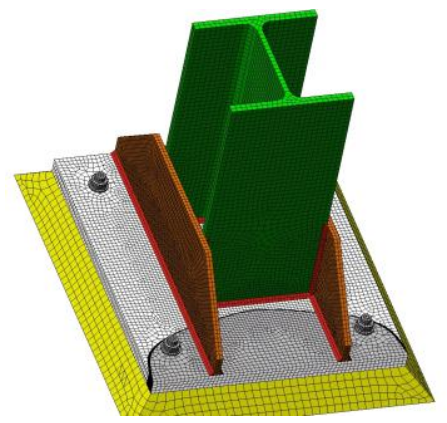

Fig. 2. The range of compressed zone (grey colour) for eccentricity $e=2,5 \mathrm{~m}$.
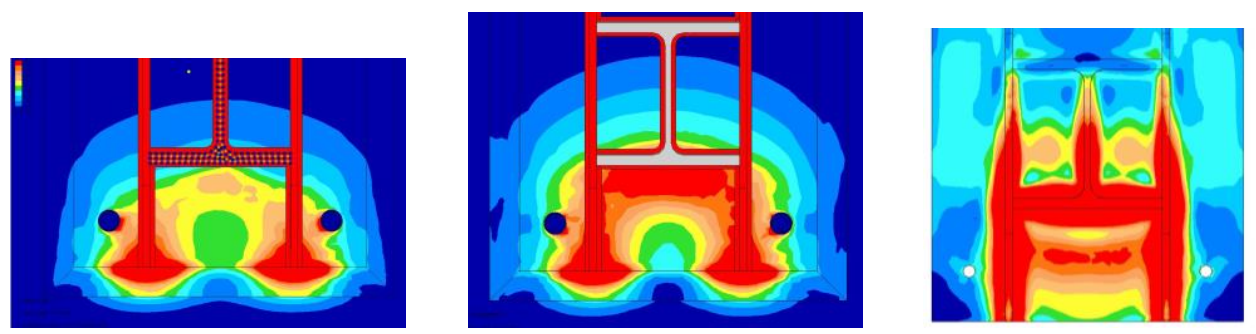

Fig. 3. Maps of compression stress under base plate for eccentricity e $=0,8 \mathrm{~m}$ (at the left), $\mathrm{e}=0,4 \mathrm{~m}$ (in the middle) and $\mathrm{e}=0,125 \mathrm{~m}$ (at the right).

The performed analysis confirms the adopted assumptions concerning the shape of a compression zone. Furthermore, the analysis reveals that the stress distribution under the column flange is not symmetrical about the flange, but it is concentrated on the side subjected to higher compression. Based on these results, the simplification rely on using only necessary part of area of equivalent T-Stubs in compression has been made (Fig. 4).
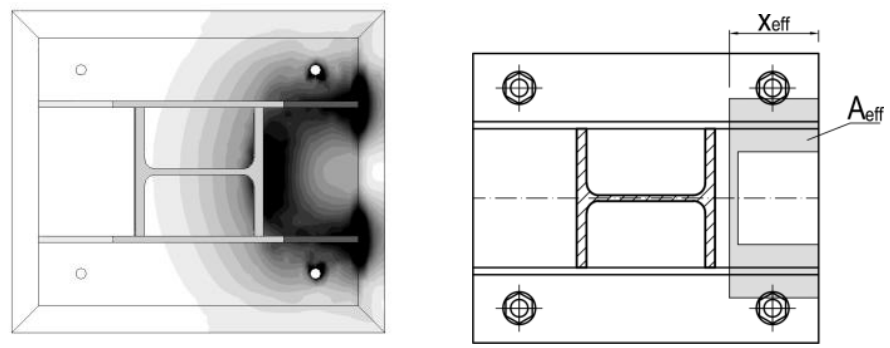

Fig. 4. Distribution of compressive stress under base plate. At the left: from FEM analysis. At the right: simplified, adopted in procedure.

According to [4] the ultimate strains in concrete $\varepsilon_{c u, 3}=3,5 \%$ (under pure bending) and $\varepsilon_{c u, 2}=2,0 \%$ (under pure compression) have been assumed in the procedure. The strain $\varepsilon_{c u, 2}$ detects more versatile character, because in ULS it always occurs at a distance $3 / 7 x$ from the ends of stiffeners, regardless of the actual value of eccentricity [6]. Therefore this point has been assumed a characteristic one for a base plate in a compressed part. The total vertical displacement of a base plate in this point $\left(\Delta C_{c u 2}\right)$ is equal the total vertical displacement of foundation directly under it. The vertical displacement of any point of the top surface of foundation is given by the expression (2):

$$
\Delta C(x, y)=\int_{0}^{h_{f}} \varepsilon_{z}(x, y, z) d z
$$


where:
$\varepsilon_{z}(x, y, z)$
the function of distribution of vertical strain in foundation under pressure from the
$h_{f}$ base plate,
$x, y$
height of foundation,
$z$
coordinates of a particular point of the top surface (in horizontal plane), coordinate on vertical axis.

While the coordinates $(x, y)$ are known, the formula (2) can be written as (3):

$$
\Delta C=\int_{0}^{h_{f}} \varepsilon_{z}(z) d z
$$

where:

$\varepsilon_{z}(z)$ the function of distribution of vertical strain in foundation through the vertical axis under characteristic point of base plate in compressed part.

Finding the mathematic formula of the mentioned function is a troublesome task. Therefore simplification of $\Delta C_{c u 2}$ formula was made in the procedure. The strain distribution through the depth of foundation has been assumed as the same as the stress distribution under partially loaded areas, according to [4]. Additionally, according to [7] the ratio between loaded area $A_{c 0}$ and design area $A_{c l}$ can be assumed as (4):

$$
\sqrt{\frac{A_{c 1}}{A_{c 0}}}=1,5
$$

Thus the average strain through the height of the foundation equals (5):

$$
\varepsilon_{\text {cu } 2, \text { mean }} \approx 0,7 \cdot \varepsilon_{\text {cu2 }}=0,7 \cdot 0,002=0,0014
$$

An approximate coefficient equal 0,7 has been calculated from geometric relations.

Finally, the total vertical displacement of the base plate due to concrete deformation at a distance $3 / 7 x$ from the ends of stiffeners $\left(\Delta C_{c u 2}\right)$ is given by the formula (6):

$$
\Delta C_{c u 2}=h_{f} \cdot \varepsilon_{c u 2, s r}=0,0014 \cdot h_{f}
$$

\subsection{Tension zone}

The tension zone consists of a base plate in bending and anchor bolts in tension. The resistance of this zone $\left(F_{T, R d}\right)$ depends on failure mode of equivalent T-Stub in tension complete yielding of the flange (mode 1-2) or anchor bolt failure (mode 3 ). In both cases reaching a full resistance of tension zone needs necessary vertical displacement of base plate at the location of anchor bolts. This displacement depends on vertical displacement of stiffeners and the stiffness of tension zone.

Vertical displacement of stiffeners in the line of anchor bolts $\left(\Delta L_{T}\right)$ is proportional to displacement in compression zone $\Delta C_{c u 2}$, according to the formula (7):

$$
\Delta L_{T}=\frac{7}{4} \cdot \Delta C_{c u 2} \cdot\left(\frac{a_{p}-e_{1}}{x}-1\right)
$$

where:

$a_{p} \quad$ length of base plate,

$e_{1} \quad$ distance from the tension edge of base plate to the centre of anchor bolts (Fig. 5). 


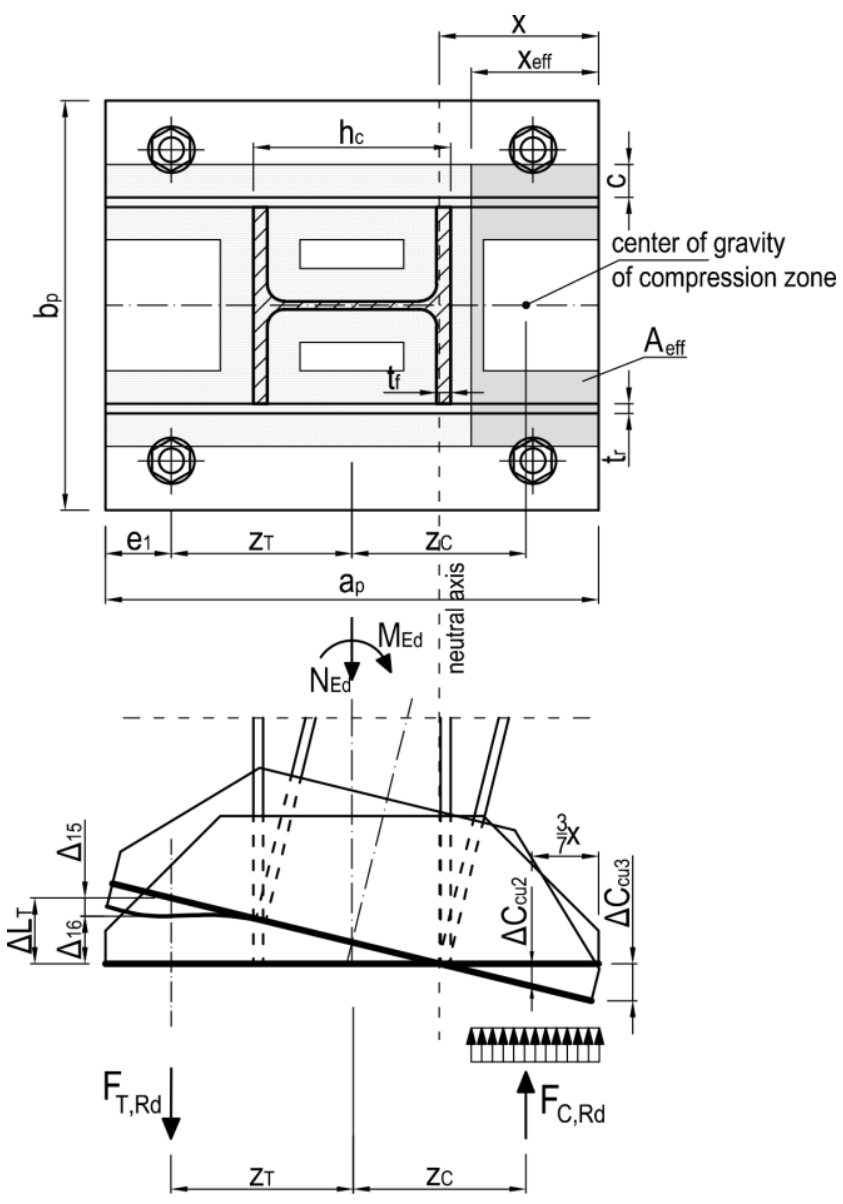

Fig. 5. Scheme of distribution of forces and displacements in column base.

According to [1] the stiffness of tension zone of column base can be written as (8):

$$
S_{T}=\frac{E}{\mu\left(\frac{1}{k_{15}}+\frac{1}{k_{16}}\right)}
$$

where:

$k_{15} \quad$ stiffness coefficient of base plate in bending under tension

$k_{16} \quad$ stiffness coefficient of anchor bolts in tension

$\mu \quad$ stiffness ratio $S_{j, i n i} / S_{j}$

E modulus of elasticity

The value of stiffness ratio $\mu$ depends on the ratio $M_{j, E d} / M_{j, R d}$, in the case of column bases can be written as (9):

$$
\mu=\left\{\begin{array}{ccc}
1,0 & \text { for } & M_{j, E d} \leq \frac{2}{3} M_{j, R d} \\
\left(1,5 \cdot \frac{M_{j, E d}}{M_{j, R d}}\right)^{2,7} & \text { for } & M_{j, E d}>\frac{2}{3} M_{j, R d}
\end{array}\right.
$$


Therefore, if $M_{j, E d}=M_{j, R d}$ then $\mu \approx 3,0$ and the required vertical displacement of stiffeners in the line of anchor bolts to achieve the full resistance of tension zone $\left(\Delta L_{T, R d}\right)$ equals (10):

$$
\Delta L_{T, R d}=\frac{F_{T, R d}}{S_{T}}=\frac{F_{T, R d} \cdot \mu}{E} \cdot\left(\frac{1}{k_{15}}+\frac{1}{k_{16}}\right)=\frac{3 \cdot F_{T, R d}}{E} \cdot\left(\frac{1}{k_{15}}+\frac{1}{k_{16}}\right)
$$

While $\Delta L_{T} \geq \Delta L_{T, R d}$ the resistance of tension zone is full, equal $F_{T, R d}$. Otherwise this resistance will be reduced to a certain value $F_{T, R d \text {,red. }}$ The dependency between $F_{T, R d \text {,red }}$ and $\Delta L_{T}$ has been assumed as the same as between bending moment in joint $M_{j, E d}$ and the rotational stiffness $\phi$, according to [1], which results in formula (11):

$$
F_{T, R d, \text { red }}=\left\{\begin{array}{cc}
\frac{\Delta L_{T} \cdot E}{\frac{1}{k_{15}}+\frac{1}{k_{16}}} & \text { for } F_{T, R d, \text { red }} \leq \frac{2}{3} F_{T, R d} \\
\left(\frac{\Delta L_{T} \cdot E \cdot F_{T, R d}^{2,7}}{3 \cdot\left(\frac{1}{k_{15}}+\frac{1}{k_{16}}\right)}\right)^{0,27} & \text { for } \quad F_{T, R d, \text { red }}>\frac{2}{3} F_{T, R d}
\end{array}\right.
$$

If $\Delta L_{T} \leq 0$ there is no tension zone in column base and $F_{T, R d, r e d}=0$.

\section{Steps of the procedure}

The procedure to compute bending resistance of the column base consists of the steps:

Step 1: Calculation of the resistance of tension zone $F_{T, R d}$ and the associated necessary displacement $\Delta L_{T, R d}(10)$.

Step 2: If necessary, assumption the reduced resistance of tension zone $F_{T, R d \text {,red }}$ due to insufficient displacement in this zone.

Step 3: Calculation of the required resistance of compression zone using formulas (12a) or $(12 b)$ :

$$
\begin{aligned}
& F_{C, R d}=F_{T, R d}+N_{E d} \\
& F_{C, R d}=F_{T, R d, r e d}+N_{E d}
\end{aligned}
$$

Step 4: Determining the range of compression zone $x_{\text {eff }}$ and $x$.

Step 5: Calculation of the vertical displacement of tension zone $\Delta L_{T}$ (7) and comparison with $\Delta L_{T, R d}(10)$.

Step 6: If necessary, calculation of the actual resistance of tension zone $F_{T, R d \text {,red }}(11)$ and comparison with assumed in step 2 . In the case of discrepancies repeating steps $2-6$ until satisfactory compatibility is reached.

Step 7: Calculation of the bending resistance using formula (13a) or (13b):

$$
\begin{aligned}
& M_{j, R d}=F_{C, R d} \cdot\left(z_{C}+z_{T}\right)-N_{E d} \cdot z_{T} \\
& M_{j, R d}=F_{C, R d} \cdot z_{C}+F_{T, R d, r e d} \cdot z_{T}
\end{aligned}
$$




\section{Design example}

The calculation of bending resistance of an exemplary column base under $\mathrm{N}_{\mathrm{Ed}}=200 \mathrm{kN}$ (Fig. 6) using proposed procedure has been presented below.
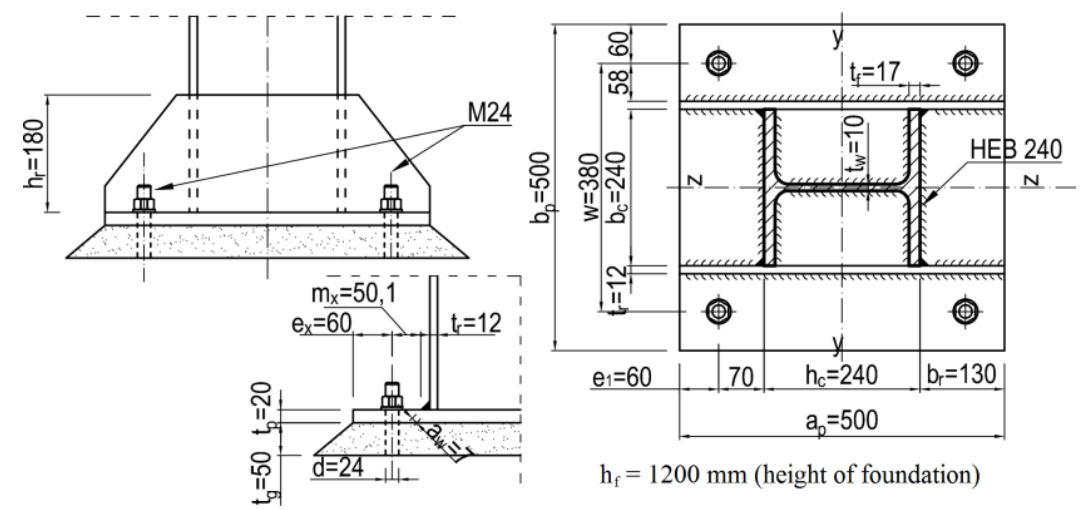

Fig. 6. Dimensions of analyzed column base.

Step 1: Calculation the resistance of tension zone and necessary displacement to achieve the full resistance of this zone:

$$
\begin{gathered}
F_{T, R d}=185,6 \mathrm{kN} \\
\Delta L_{T, R d}=\frac{3 \cdot F_{T, R d}}{E} \cdot\left(\frac{1}{k_{15}}+\frac{1}{k_{16}}\right)=\frac{3 \cdot 185600}{210000} \cdot\left(\frac{1}{5,34}+\frac{1}{2,57}\right)=1,53 \mathrm{~mm}
\end{gathered}
$$

Step 2: Assumption the reduced resistance of tension zone due to insufficient displacement in this zone:

Assumption of sufficient displacement has been made, therefore: $F_{T, R d, r e d}=F_{T, R d}$

Step 3: Calculation of the required resistance of compression zone:

$$
F_{C, R d}=F_{T, R d}+N_{E d}=185,6+200=385,6 \mathrm{kN}
$$

Step 4: Determining the range of compression zone (Fig. 7):

$$
F_{C, R d, 1}=A_{e f f, 1} \cdot f_{c d}=16880 \cdot 17,8=300,5 \mathrm{kN}
$$

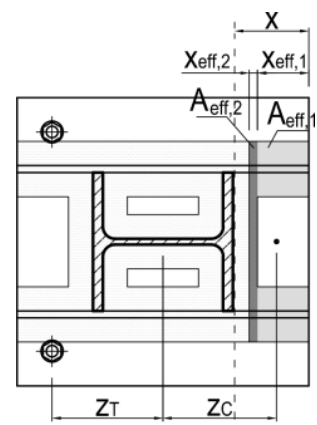

Fig. 7. The range of compression zone of analyzed column base for $\mathrm{N}_{\mathrm{Ed}}=200 \mathrm{kN}$.

$$
\begin{gathered}
F_{C, R d, 2}=F_{C, R d}-F_{C, R d, 1}=385,6-300,5=85,1 \mathrm{kN} \\
x_{e f f, 2}=13,8 \mathrm{~mm} \\
x=\frac{x_{e f f}}{\lambda}=\frac{101,9}{0,8}=127,4 \mathrm{~mm}
\end{gathered}
$$


Step 5: Calculation of the vertical displacement of tension zone:

$$
\Delta L_{T}=\frac{7}{4} \cdot \Delta C_{c u 2} \cdot\left(\frac{a_{p}-e_{1}}{x}-1\right)=\frac{7}{4} \cdot 1,68 \cdot\left(\frac{500-60}{127,4}-1\right)=7,2 \mathrm{~mm}
$$

Step 6: Calculation of the actual resistance of tension zone:

$$
\Delta L_{T}=7,2 \mathrm{~mm}>\Delta L_{T, R d}=1,53 \mathrm{~mm} \rightarrow F_{T, R d, \text { red }}=F_{T, R d}
$$

Step 7: Calculation of bending resistance:

$$
M_{j, R d}=385,6 \cdot(194,7+190) \cdot 10^{-3}-200 \cdot 190 \cdot 10^{-3}=110,5 \mathrm{kNm}
$$

The diagram with the $\mathrm{M}-\mathrm{N}$ curve for analysed geometry of column base is shown in Figure 8 . The shape of the curve is similar to the diagram for reinforced concrete columns.

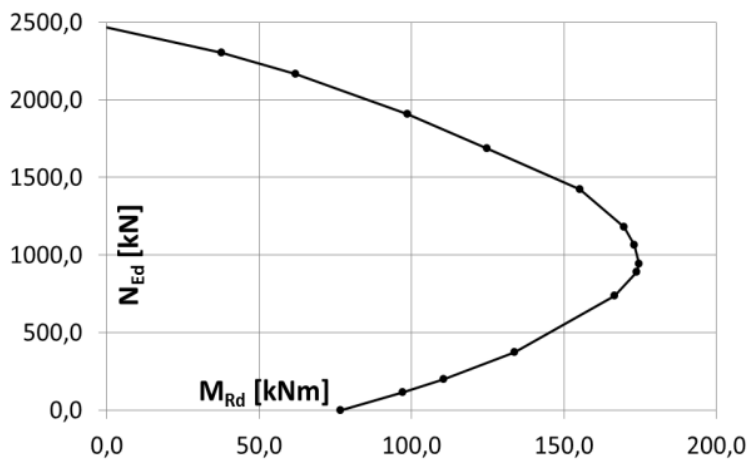

Fig. 8. The $\mathrm{M}-\mathrm{N}$ curve for analyzed geometry of column base.

\section{Conclusions}

The proposed procedure allows to easily calculate the resistance of column bases with stiffeners under any combination of loads. This universal calculation method based on Eurocode assumptions is an interesting alternative to existing procedures with many restrictions in the usage. It can be used not only for column base with stiffeners, but also for other problematic cases with complex geometry. Application of the deformation analysis allows to include together the properties of steel base plate and the concrete foundation.

\section{References}

1. EN 1993-1-8 (2005): Eurocode 3: Design of steel structures - Part 1-8: Design of joints

2. M. Łubiński, A. Filipowicz, W. Zółtowski, Konstrukcje metalowe, część I: podstawy projektowania (Arkady, Warszawa, 2000)

3. A. Matuszak, Czasopismo Techniczne, 107, 4-B, 75-86 (2010)

4. EN 1992-1-1 (2004): Eurocode 2: Design of concrete structures - Part 1-1: General rules and rules for buildings

5. J. Żmuda, Projektowanie Konstrukcji Stalowych, cz. 1 Dźwigary kratownicowe, stupy, ramownice (PWN, Warszawa, 2016)

6. A. Łapko, B. Jensen, Podstawy projektowania $i$ algorytmy obliczeń konstrukcji zelbetowych (Arkady, Warszawa, 2015)

7. Access Steel, SN037a-PL-EU 